\title{
Human judgment and health care policy.
}

\author{
Benjamin Djulbegovic \\ Morsani College of Medicine and H. Lee Moffitt Cancer Center and Research Institute \\ Jason Beckstead \\ University of South Florida College of Nursing \\ David B. Nash \\ Thomas Jefferson University
}

Follow this and additional works at: https://jdc.jefferson.edu/healthpolicyfaculty

Part of the Public Health Commons

Let us know how access to this document benefits you

\section{Recommended Citation}

Djulbegovic, Benjamin; Beckstead, Jason; and Nash, David B., "Human judgment and health care policy." (2014). College of Population Health Faculty Papers. Paper 70.

https://jdc.jefferson.edu/healthpolicyfaculty/70

This Article is brought to you for free and open access by the Jefferson Digital Commons. The Jefferson Digital Commons is a service of Thomas Jefferson University's Center for Teaching and Learning (CTL). The Commons is a showcase for Jefferson books and journals, peer-reviewed scholarly publications, unique historical collections from the University archives, and teaching tools. The Jefferson Digital Commons allows researchers and interested readers anywhere in the world to learn about and keep up to date with Jefferson scholarship. This article has been accepted for inclusion in College of Population Health Faculty Papers by an authorized administrator of the Jefferson Digital Commons. For more information, please contact: JeffersonDigitalCommons@jefferson.edu. 


\section{Point of View}

\section{Human Judgment \& Health Care Policy}

Benjamin Djulbegovic, MD, PhD ${ }^{1,2}$ Jason Beckstead, $\mathrm{PhD}^{3}$ and David B. Nash, MD, $\mathrm{MBA}^{4}$

${ }^{1}$ University of South Florida, Morsani College of Medicine, Division for Evidence-based Medicine and Health Outcomes Research, Department of Medicine, Tampa, FL; ${ }^{2} \mathrm{H}$. Lee Moffitt Cancer Center \& Research Institute, Departments of Hematology and Health Outcomes and Behavior. Tampa, FL

${ }^{3}$ University of South Florida College of Nursing, Tampa, FL

${ }^{4}$ Jefferson School of Population Health, Thomas Jefferson University, Philadelphia, PA

Corresponding Author:

Benjamin Djulbegovic, MD, PhD

Division of Evidence-based Medicine, Department of Internal Medicine

University of South Florida; and H. Lee Moffitt Cancer Center \& Research Institute

Mailing Address:

3515 East Fletcher Avenue, MDT 1201, MDC 27

Tampa, FL 33612

Phone: 813-396-2349

Fax: 813-905-8909

e-mail: $\underline{\text { bdjulbeg@health.usf.edu }}$ 


\section{Conflict of interest}

Dr. Djulbegovic, Dr. Beckstead, and Dr. Nash declare no conflicts of interest with respect to the research, authorship, and/or publication of this article. The authors received no financial support for the research, authorship, and/or publication of this article. 
Modern health care is increasingly fragmented (eg, a typical elderly patient sees 411 physicians ${ }^{1}$ ), poorly coordinated (eg, a physician may need to coordinate with 99 other physicians in 53 different practices for every 100 Medicare patients seen²), wasteful (eg, $30 \%-50 \%$ of health care is inappropriate or unnecessary), ${ }^{3,4}$ and often does more harm than good (eg, 40,000-98,000 people die each year from medical errors). ${ }^{5}$ To date, 4 major responses have been offered to improve the current less-than-ideal situation in health care: (1) promotion of a culture of accountability and performance based on quality of care measurements, (2) implementation of systems to minimize medical errors, (3) economic incentives to minimize financial conflict of interests (often seen as drivers of inappropriate care), and (4) incorporation of comparative effectiveness research and evidence-based medicine as a key scientific foundation. So far, evidence that any of these initiatives has had a meaningful impact on delivery of health care is lacking. Unfortunately, the effect of each of these otherwise worthy programs likely will remain modest until they take into consideration the key factor(s) behind the failure to deliver safe and (cost-) effective health care: the role of physicians' judgment. ${ }^{6}$ How physicians process information when making health care decisions ultimately affects patient outcomes. Given that $80 \%$ of all health care expenditures are affected by physicians' decisions ${ }^{7}$ and that poor decisions represent the leading cause of death, ${ }^{8}$ it would serve us well to better understand the cognitive processes and constraints that are placed on physicians. 
To start, we should contrast the sheer volume of information facing modern physicians with the human brain's limited capacity for information processing and storage. The span of absolute judgment and the span of immediate memory impose severe limitations on the amount of information we are able to receive, process, and remember; we can handle only about $7 \pm 2$ distinct pieces of information at any one time. ${ }^{9}$ Our absolute judgment is limited by the complexity (amount in bits) of the information we attempt to process while our immediate memory is limited by the number of items we can store and retrieve when making decisions. Yet, we work in an environment characterized by staggering information overload. ${ }^{10}$

Physicians are required to instantaneously recall more than 2 million facts and integrate more than 1000 pieces of data that characterize every clinical encounter; medical students are expected to read more than 11,000 pages per year, and keep up with medical knowledge that approximately doubles every decade relating to more than 30,000 diseases that can present with an infinite number of combinations. ${ }^{11}$ MEDLINE alone contains over 18 million references from approximately 5516 journals. ${ }^{12}$ In their attempt to deal this with enormous amount information, physicians use both intuitive and deliberative cognitive processes, with the tendency to use the least possible effort to engage in problem solving and decision making. ${ }^{13}$ 
The presumed goal of maximizing clinical decision quality is virtually unrealizable owing both to the complexity of the health care system and the limitations of human information processing. Instead, physicians often have to pursue the goal of "satisficing" rather than "maximizing." ${ }^{14}$ To "satisfice" is to choose a decision option (eg, diagnosis, treatment) that is deemed "good enough" given the number and utility of choices available, the time allowed to make a choice, and the amount of cognitive effort involved. When time is limited, such as during a typical 11-minute clinical encounter, ${ }^{15}$ with less than 2 minutes available to search for reliable information, ${ }^{16}$ and being interrupted every 15 minutes on average ${ }^{17}$ physicians are forced to satisfice.

"Satisficing," although it may be "good enough," also means that errors and lapses in judgment will inevitably occur resulting in suboptimal health outcomes and the waste of resources. Under these circumstances, a typical decision-making strategy is to issue requests for more "consults" and to order more tests. Although some of these requests are appropriate, many are not. If, for example, the patient complains of a cough, a typical reaction would be to ask for a "pulmonary consult" and to order a chest X-ray (and not uncommonly a computerized tomography chest/angiogram), but rarely to retake a careful history and physical exam -2 time-consuming activities. Similarly, a hematology consultant would be called for a drop in platelets, nephrology for an increase in creatinine, cardiology for chest pain, neurology for headache, gastroenterology for nausea, and so on. Once on the case, each of the consultants 
typically continues to manage the patient, adding to further fragmentation of care and creating the conditions for poor care coordination; with more decisions being made by more and more individuals, the probability for error increases. Hence, suboptimal outcomes documented in health care are related, in part, to the environment overwhelming the cognitive information processing capacity that physicians rely upon.

Another important aspect of clinical decision making is that the advent of the Internet has refocused cognitive strategies toward recalling and searching information external to one's own memory. ${ }^{18}$ However, today's search engines and existing medical information delivery services, while awe-inspiring in the volume of information they can process, are woefully inadequate at delivering patient-specific reliable evidence in a timely manner.

Given that medical science and human judgment are what they are, is there a solution to the problem described herein? We think the solution flows from understanding the cognitive processes that underpin physicians' decision making and the nature of the decision environment in which they operate. We need to recognize that the irreducible uncertainty inherent in medical science coupled with situational factors, among which time pressure is a chief determinant, predispose physicians to pursue satisficing decision strategies. It has been said that "time is greatest commodity of our times." Therefore, the single most important factor that would help physicians' 
cognitive effort is to allow physicians to have more time with patients and more time to search for information to deal with information overload. ${ }^{10}$ If we are going to promote a culture in which quality of care matters, we need to understand that, once professional competence is achieved, there is a reciprocal relationship between the quantity and quality of decisions that can be made. Decision quality may be improved by increasing the time allotted for each patient encounter, and by increasing the efficiency of information processing during the encounter. In the foregoing example, if an admitting physician had more time to see each patient and search for information, he or she would be better able to diagnose and manage conditions while minimizing resource waste. Hence, physicians should be incentivized to spend more time with their patients.

Nevertheless, the clinical encounter cannot be unlimited. Providing better (ie, faster) and more focused tools for obtaining reliable information during each visit ideally within 2-5 minutes ${ }^{19}$ - is key to improving decision quality. As the amount of information available to physicians is only going to increase in the $21^{\text {st }}$ century, developing search tools that augment, rather than overwhelm, the processing limits of the human mind should be a key research priority that ultimately will pay off in better clinical decision making and improved patient outcomes. 


\section{References}

1. Pham HH, Schrag D, O'Malley AS, Wu B, Bach PB. Care patterns in Medicare and their implications for pay for performance. N Engl J Med. 2007;356(11):1130-1139.

2. Pham HH, O'Malley AS, Bach PB, Saiontz-Martinez C, Schrag D. Primary care physicians' links to other physicians through Medicare patients: the scope of care coordination. Ann Intern Med. 2009;150:236-242.

3. Manchikanti L, Falco FJ, Boswell MV, Hirsch JA. Facts, fallacies, and politics of comparative effectiveness research: Part 2 - implications for interventional pain management. Pain Physician. 2010;13(1):E55-79.

4. Berwick DM, Hackbarth AD. Eliminating waste in US health care. JAMA. 2012;307:15131516.

5. Institute of Medicine. To Err Is Human: Building a Safer Health System. Washington, DC: National Academies Press; 2000.

6. Hammond KR. Human Judgment and Social Policy. Irreducible Uncertainty, Inevitable Error, Unavoidable Injustice. Oxford: Oxford University Press; 1996.

7. Cassel CK, Guest JA. Choosing wisely. JAMA. 2012;307:1801-1802.

8. Keeney RL. Personal decisions are the leading cause of death. Operations Research. 2008;56:1335-1347.

9. Miller G. The magical number seven, plus or minus two: some limits on our capacity for processing information. Psychological Review. 1956;63:81-97.

10. Gleick J. The Information: A History, A Theory, A Flood. 1st ed. New York: Pantheon Books; 2011.

11. Djulbegovic B, Lyman GH, Ruckdeschel J. Why evidence-based oncology? Evidence-based Oncology. 2000;1:2-5.

12. National Institutes of Health, US National Library of Medicine. MEDLINE: Fact Sheet. http://www.nlm.nih.gov/pubs/factsheets/medline.html. Accessed March 8, 2014.

13. Djulbegovic B, Beckstead JW, Elqayam S, et al. Evaluation of physicians' cognitive styles. Med Decision Making. In press.

14. Simon HA. A behavioral model of rational choice. Quart J Economics. 1955;69:99-118.

15. Gottschalk A, Flocke SA. Time spent in face-to-face patient care and work outside the examination room. Ann Fam Med. 2005;3:488-493.

16. Ely JW, Osheroff JA, Ebell MH, Bergus GR, Levy BT, Chambliss ML. Analysis of questions asked by family doctors regarding patient care. BMJ. 1999;319:358-361.

17. O'Leary KJ, Liebovitz DM, Baker DW. How hospitalists spend their time: insights on efficiency and safety. J Hosp Med. 2006;1:88-93.

18. Sparrow B, Liu J, Wegner DM. Google effects on memory: cognitive consequences of having information at our fingertips. Science. 2011;333(6043):776-778.

19. Muir Gray JA, Lusignan Sd. National electronic Library for Health (NeLH). BMJ. 1999;319:1476-1479. 